\title{
Interaction of the $\mathrm{La}^{3+}$-Morin Complex with DNA
}

\author{
Xiao-jing LIU, Yuan-zong $\mathrm{LI}$ and Yun-xiang $\mathrm{CI}^{\dagger}$ \\ Department of Chemistry, Peking University, Beijing 100871, P. R. China
}

\begin{abstract}
The interaction of the $\mathrm{La}^{3+}$-morin complex with DNA has been examined using fluorescence and absorption spectroscopic as well as viscosity measurement methods. The fluorescence intensity of $\mathrm{La}^{3+}$-morin complex could be highly enhanced by DNA. In the presence of DNA the absorption wavelength or fluorescence excitation wavelength showed a red shift of $43-45 \mathrm{~nm}$, while the emission wavelength remained unchanged, consistent with groove binding of fluorescent dye with DNA. In contrast to intercalators, the complex showed an enhanced stacking effect, based on a viscometer measurement, on base pairs of DNA. The presence of both $\mathrm{NaCl}$ and phosphate showed a strong quenching effect on the fluorescence of the ternary system. This is also in favor of groove binding. Thus, groove binding rather than intercalation of the complex to DNA was suggested. Binding of the complex into a DNA narrow minor groove imposed constrains on free motion of the complex. Therefore, the non-radioactive deactivation of the excited state of the complex was inhibited and fluorescence enhancement was observed. The enhancement effect of DNA on the fluorescence of $\mathrm{La}^{3+}$ morin complex was used for a quantitative and selective determination of d.juble-stranded DNA. The detction limit was $20 \mathrm{ng} / \mathrm{ml}$.
\end{abstract}

Keywords Nucleic acid, La-morin complex, fluorescence enhancement

Nucleic acids interact with a broad range of chemical species that include small organic cations, drugs, ions and their complexes, most of which show probe properties due to their specific interaction with nucleic acid. These interactions have provided much of our most accurate information about nucleic acid binding specificity, ligand-induced conformational transitions and other similar critical features of nucleic acid interaction and chemistry. ${ }^{1}$ In the context of the analytical purpose two major types of fluorescence probes have been intensively studied. One is organic dyes that interact with DNA by intercalation or minor groove binding. Another type is $\mathrm{Eu}^{3+}, \mathrm{Tb}^{3+}$ or their complexes that interact with DNA in different ways ${ }^{2-6}$ and some of these complex systems can be used for DNA analysis. One common aspect is that nearly all of the probes share more or less positive charges. This is simply due to the fact that nucleic acids are highly charged polyelectrolytes that take negative charges under the physiological conditions. This is also an indication of the importance of an electrostatic interaction between nucleic acids and these probes. Morin is a flavone-type natural compound (see Fig. 1) that shows high anti-bacteria and anti-virus activities. It showed a similarity to tetracycline analogues in the binding of metal ions, such as alkaline earth and lanthanide ions, that play a determining role in the bacteriostatic properties of the antibiotics. ${ }^{7,8}$ In this study, the interaction between $\mathrm{La}^{3+}$-morin complex and nucleic acid was investigated. This may provide some

† To whom correspondence should be addressed.<smiles>O=C1C(O)=C2Oc3cc(O)ccc3C1(O)c1c(O)cc(O)cc1O2</smiles>

Fig. 1 The structure of morin.

information on the interaction of nucleic acids with morin in living systems where high concentrations of $\mathrm{Mg}^{2+}$ and $\mathrm{Ca}^{2+}$ may act like $\mathrm{La}^{3+}$ in this case. Previously, the fluorescence complexes of morin with a number of ions, such as $\mathrm{Al}^{3+}, \mathrm{La}^{3+}, \mathrm{Sc}^{3+}$ and $\mathrm{Zf}^{4+}$, have been widely used for the quantitative determination of these ions. ${ }^{9}$ In this study, the high fluorescence enhancement effect of DNA on $\mathrm{La}^{3+}$-morin complex was used for quantitative determination of natural DNA.

\section{Experimental}

\section{Materials}

Commercially prepared calf thymus (CT) DNA and yeast RNA (Baitai Biochemicals, China) were suspended directly in water to make a stock solution with $100 \mu \mathrm{g} / \mathrm{ml}$ of DNA or RNA. The denatured DNA solution was prepared by heating a natural DNA solution in a boiling water bath for $15 \mathrm{~min}$. Then, the solution was cooled in an ice bath. A stock solution of $\mathrm{La}^{3+}$ or other lanthanide 
ions $\left(1.0 \times 10^{-3} \mathrm{~mol} / \mathrm{l}\right)$ was prepared by dissolving each lanthanide oxide (Beijing Xinxin Chemicals, China) in concentrated hydrochloric acid; the solution was evaporated to dryness. The residue was dissolved in $0.1 \mathrm{~mol} / 1$ hydrochloric acid. A stock solution of morin $\left(1.0 \times 10^{-3} \mathrm{~mol} / \mathrm{l}\right)$ was prepared by dissolving $0.0169 \mathrm{~g}$ of morin (Beijing Chemicals Factory, China) in a small amount of $0.1 \mathrm{~mol} / 1 \mathrm{NaOH}$ and then diluted to $100 \mathrm{ml}$ in a volumetric flask. More diluted solutions of above reagents were prepared all by appropriate dilution with water. Acetate buffer (HOAc-NaOAc) solution was used for maintaining the $\mathrm{pH}$. Other chemicals used were all of analytical grade and doubly deionized water was used throughout this study.

\section{Instruments}

The fluorescence spectra and intensities were measured on a Perkin Elmer LS-50B spectrofluorometer with a pulse xenon lamp and dual monochromators. Both excitation and emission slits were maintained at $10 \mathrm{~nm}$. UV spectra were recorded on a Shimadzu UV-3100, and the viscosity was measured by a capillary method with a tri-tube viscometer.

\section{General experimental procedures}

Typically, samples containing appropriate concentrations of morin, DNA and $\mathrm{La}^{3+}$ ion were made up to $10 \mathrm{ml}$ in acetate buffer ( $\mathrm{pH}$ 5.5). The wavelengths were $\lambda_{\mathrm{ex}}=$ 438 and $\lambda_{\mathrm{em}}=505 \mathrm{~nm}$. Fluorescence readings were given as net fluorescence intensities in arbitrary units of the instrument. The background had been subtracted from each value reported, except for those in the excitation and emission spectra.

\section{Results and Discussion}

\section{Characteristics of fluorescence spectra}

The fluorescence excitation and emission spectra of morin and $\mathrm{La}^{3+}$-morin binary systems in the presence and absence of DNA are shown in Fig. 2. The results show that the addition of $\mathrm{La}^{3+}$ to morin solution had a very small fluorescence enhancement effect. In addition, both the excitation and emission spectra of morin remain unchanged, showing a very weak interaction between morin and $\mathrm{La}^{3+}$, or a small influence of this binary complex formation on the fluorescence property of morin under the experimental conditions. The addition of DNA to a morin solution showed a lightly greater fluorescence enhancement. In the meantime, a red shift $(15 \mathrm{~nm})$ of the maximum excitation wavelength from $395 \mathrm{~nm}$ for the free morin to $410 \mathrm{~nm}$ for the bound morin was observed, indicating the existence of an interaction between the morin and DNA in the absence of $\mathrm{La}^{3+}$. When DNA was added to a $\mathrm{La}^{3+}$-morin complex solution, a great fluourescence enhancement (about 25 times) and a large red shift of $43 \mathrm{~nm}$, relative to the free morin, for the maximum excitation wavelength appeared, indicating ternary complex formation and an enhanced

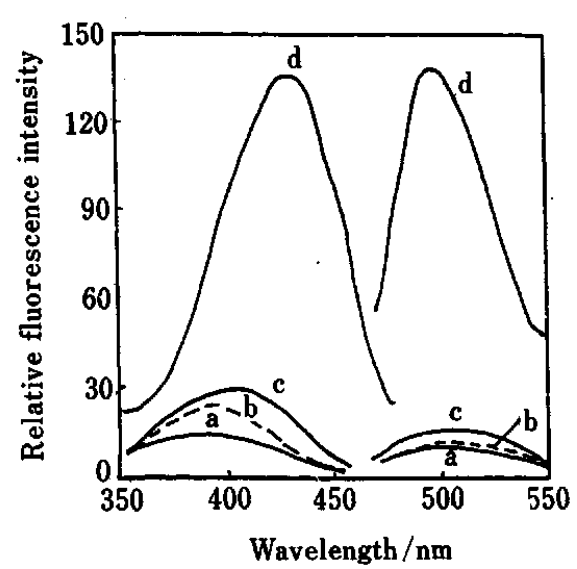

Fig. 2 The fluorescence excitation $(E m=505 \mathrm{~nm})$ and emission $(\mathrm{Ex}=438 \mathrm{~nm})$ spectra of morin and $\mathrm{La}^{3+}$-morin binary complex in the presence and absence of DNA at pH 5.5. (a) $1.0 \times 10^{-5} \mathrm{~mol} / 1 \mathrm{morin}$; (b) $1.0 \times 10^{-5} \mathrm{~mol} / 1 \mathrm{morin}+1.0 \times 10^{-5}$ $\mathrm{mol} / 1 \mathrm{La}^{3+}$; (c) $1.0 \times 10^{-5} \mathrm{~mol} / 1 \mathrm{morin}+4.0 \mu \mathrm{g} / \mathrm{ml} \mathrm{DNA}$; (d) $1.0 \times 10^{-5} \mathrm{~mol} / 1 \mathrm{morin}+1.0 \times 10^{-5} \mathrm{~mol} / 1 \mathrm{La}^{3+}+4.0 \mu \mathrm{g} / \mathrm{ml}$ DNA.

interaction between the DNA and morin. In all of the cases the maximum emission wavelength remained at $505 \mathrm{~nm}$.

Similar results were obtained when yeast RNA or denatured DNA was used instead of natural DNA. However, the red shift of the excitation wavelength was only $15 \mathrm{~nm}$, much less than $43 \mathrm{~nm}$ in the natural DNA system. The fluorescence enhancement effect was about $25 \%$ of that in the case of natural DNA. These results indicate that $\mathrm{La}^{3+}$-morin had specificity in binding to double-stranded natural DNA. The red shift of the excitation wavelength suggests either a groove or intercalation binding mode, while a constant emission wavelength is in favor of groove binding. ${ }^{9}$ Ring $\mathrm{C}$ of morin may rotate. Therefore, morin and its complex with $\mathrm{La}^{3+}$ may not favor a plannar geometry, and the binding of $\mathrm{La}^{3+}$-morin complex to DNA should disfavor the intercalation mode. The fluorescence enhancement may be due to the binding of the $\mathrm{La}^{3+}$-morin complex to the narrow minor groove of DNA, that would impose restrictions on the rotation of ring $\mathrm{C}$ of morin and increase the rigidity of $\mathrm{La}^{3+}$-morin complex. Furthermore, the electrostatic interaction plus close van der Waals contacts with the "walls" of the minor groove may exclude water molecules from the complex and, therefore, supress a non-radioactive deactivation and increase the fluorescence quantum yield.

\section{Characteristics of UV spectra}

The absorption spectra of morin and its complex with $\mathrm{La}^{3+}$ in the presence of different concentrations of DNA are shown in Fig. 3. Morin showed a red shift of $15 \mathrm{~nm}$ in the presence of $\mathrm{La}^{3+}$ together with a slight decrease in the peak intensities, indicating a complex formation between $\mathrm{La}^{3+}$ and morin. This is slightly different from 


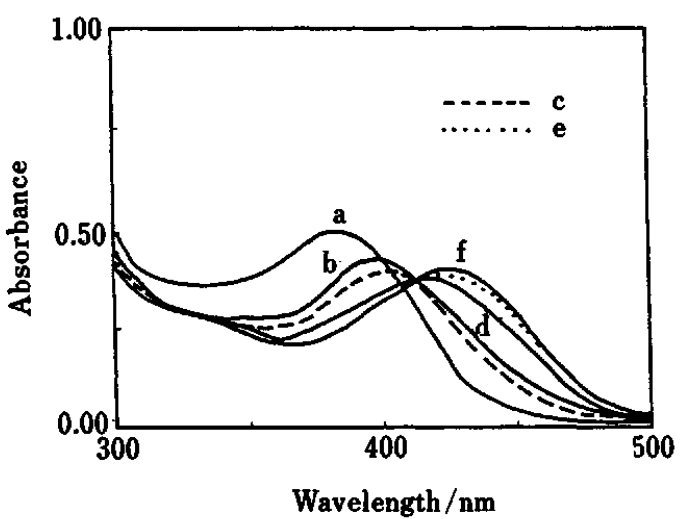

Fig. 3 The UV spectra of $4.0 \times 10^{-5} \mathrm{~mol} / 1$ morin (a) and $4.0 \times 10^{-5} \mathrm{~mol} / 1 \mathrm{morin}+4.0 \times 10^{-5} \mathrm{~mol} / 1 \mathrm{La}^{3+}+\mathrm{DNA}$ at $\mathrm{pH} 5.5$. The concentrations of DNA were $0,20,100,200$ and $400 \mu \mathrm{g} /$ $\mathrm{ml}$, respectively, from curves $\mathrm{b}$ to $\mathrm{f}$.

that observed from the fluorescence excitation spectrum, where no apparent red shift was found in the binary system. This implies that binary complex formation had a very small influence on the fluorescence enhancement and, therefore, the expected excitation wavelength shift was not found. Thus, the interaction between DNA and morin should have played a determining role in the fluuorescence enhancement. Upon the addition of DNA to the $\mathrm{La}^{3+}$-morin system with increasing concentration, a isosbestic point at $412 \mathrm{~nm}$ appeared and the absorption band gradually moved to $430 \mathrm{~nm}$, indicating ternary complex formation. A red shift of $45 \mathrm{~nm}$ relative to morin was in good agreement with that observed in the fluorescence excitation wavelength shift under similar conditions. The red shift is common in the drug-DNA interaction. The addition of DNA did not show evident hypochromism that usually accompanies the intercalation of dye, such as ethidium, into base stack of DNA. ${ }^{9}$ This result was also in agreement with the groove binding of the complex to DNA, rather than intercalation.

If the concentration of DNA remained constant at $1.1 \times 10^{-4} \mathrm{~mol} / 1$ (in phosphate) and it was titrated with $\mathrm{La}^{3+}$-morin $(1: 1)$ complex by increasing the molar ratio of the $\mathrm{La}^{3+}$-morin complex to DNA $\left(r_{\mathrm{b}}\right)$, the absorption of DNA could be used as an indication of the interaction between DNA and the $\mathrm{La}^{3+}$-morin complex. The results in Fig. 4 showed that when $r_{\mathrm{b}}=0.09$, only small decrease in UV absorption of DNA was observed. However, when $r_{\mathrm{b}}$ was increased, in turn, to $0.47,0.71$ and 0.94 , a gradual hypochromism along with red shift of absorption band was observed. This characteristic is closely related to the double-helices structure of DNA, which involves a stack of nucleic bases. The observed hypochromic and bathochromic shifts indicate that the presence of $\mathrm{La}^{3+}$ morin complex strengthened the stacking of DNA bases or shortened DNA length. This was probably by virtue of the neutralization of negative charges of DNA molecules, which leads to a decreased repeling among

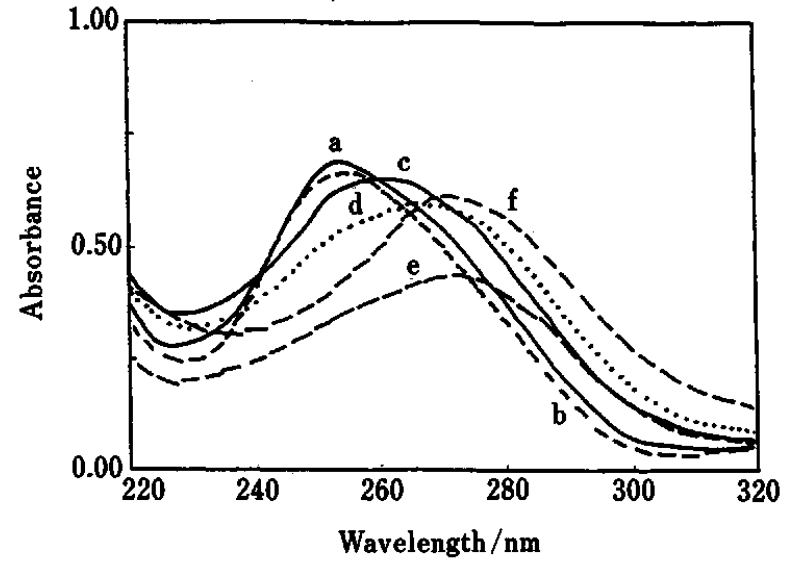

Fig. 4 The effect of $\mathrm{La}^{3+}$-morin complex on the absorption of $50 \mu \mathrm{g} / \mathrm{ml}$ DNA at $\mathrm{pH}$ 5.5. The molar ratios of $\mathrm{La}^{3+}$-morin complex and DNA phosphate were 0, 0.09, 0.47, 0.71, 0.94 and 1.89 , respectively, from curves a to $f$.

negatively charged phosphate groups. A further increase of $r_{\mathrm{b}}$ (for example, $r_{b}=1.89$ ) led to a hyperchromic effect. This indicated that a too high concentration of $\mathrm{La}^{3+}$-morins is not favorable for DNA stacking. Although an evident increase of UV absorption was observed, it could not exceed the intensity of undisturbed natural DNA, even when the concentration of $\mathrm{La}^{3+}$ morin was quite high. DNA denaturation would not occur in the presence of the $\mathrm{La}^{3+}$-moring complex with $r_{\mathrm{b}}$ up to 10 , since evident hyperchromism accompanying DNA denaturation was not observed. The influence of the $\mathrm{La}^{3+}$-morin complex on DNA base stacking was further studied by comparing the viscosities of a DNA solution in the presence of ethidium bromide (EB) and the $\mathrm{La}^{3+}$-morin complex.

\section{Influence of EB and $\mathrm{La}^{3+}$-morin complex on the viscosity of DNA solution}

According to ref. 11

$$
\frac{L}{L_{0}}=\left(\frac{\eta}{\eta_{0}}\right)^{1 / 3}
$$

In the above expression $L_{0}$ and $L$ are the lengths of DNA in the absence and presence of EB or the $\mathrm{La}^{3+}$ moring complex, respectively, and $\eta_{0}$ and $\eta$ the viscosities of the corresponding aqueous DNA solution.

The relative viscosity of DNA solutions was measured at $20^{\circ} \mathrm{C}$ in a standard manner in the presence of different concentrations of $\mathrm{EB}$ and the $\mathrm{La}^{3+}$-morin complex. The results are illustrated in Fig. 5.

Evidently, the viscosity of the DNA solution was increased when EB was added, indicating the intercalation of EB into the base pairs of double-helical DNA and stretching of the DNA strand. When $r_{\mathrm{b}}$ reached 0.28 and above, the intercalation was saturated and the viscosity remained unchanged. This was in good agreement with a previous report. ${ }^{11}$ The addition of the 


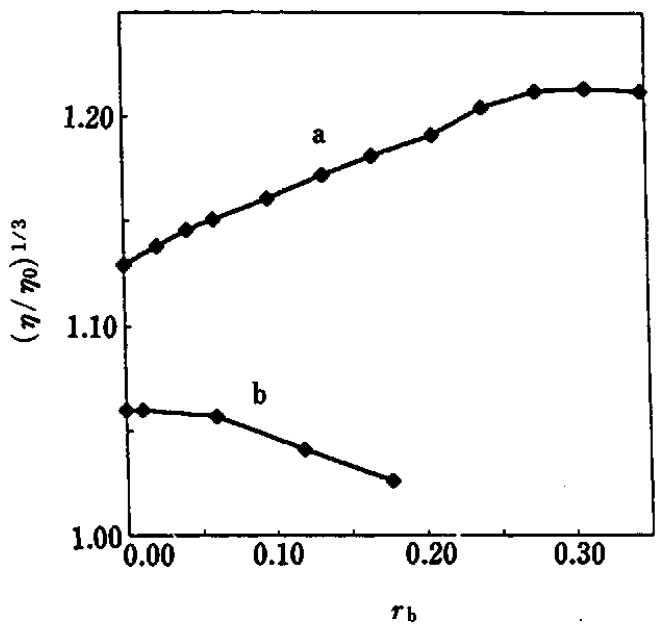

Fig. 5 The influence of EB (a) and $\mathrm{La}^{3+}$-morin complex (b) on the viscosity of a $285 \mu \mathrm{g} / \mathrm{ml}$ DNA solution. The experiments were carried out in $0.01 \mathrm{~mol} / \mathrm{I}$ Tris- $\mathrm{HCl}(\mathrm{pH} \mathrm{7.4)}$ and $0.02 \mathrm{~mol} / 1$ acetate buffer solution (pH 5.5), respectively.

$\mathrm{La}^{3+}$-morin complex, compared with that of EB, showed a different influence on the viscosity of the DNA solution. This implied that the interaction mechanisms of $\mathrm{EB}$ and the $\mathrm{La}^{3+}$-morin with DNA were different. This also supported non-intercalative interaction mechanisms between the DNA and the $\mathrm{La}^{3+}$-morin complex. While a low concentration of the $\mathrm{La}^{3+}$-morin complex showed little influence on the viscosity of the DNA solution, a higher concentration $\left(r_{\mathrm{b}}>0.06\right)$ decreased the viscosity of the DNA solution. This is an indication of an enhanced stacking of DNA base pairs, consistent with the hypochromic effect observed in the absorption spectra.

Quenching of fluorescence of DNA-La ${ }^{3+}$-morin ternary complex by phosphate and $\mathrm{NaCl}$

The influence of phosphate ion on the fluorescence of $\mathrm{La}^{3+}$-morin and DNA- $\mathrm{La}^{3+}$-morin systems was studied. The concentrations of $\mathrm{La}^{3+}$, morin and DNA were maintained at $1.0 \times 10^{-5} \mathrm{~mol} / \mathrm{l}, 1.0 \times 10^{-5} \mathrm{~mol} / \mathrm{l}$ and $4.0 \mu \mathrm{g} /$ $\mathrm{ml}$, respectively. Although $5.0 \times 10^{-5}$ and $1.0 \times 10^{-4} \mathrm{~mol} /$ 1 concentrations of phosphate showed no influence on the fluorescence of the $\mathrm{La}^{3+}$-morin system, quenching of fluorescence by 12 and $43 \%$, repectively, was observed for DNA-La ${ }^{3+}$-morin. This is understandable since competitive binding of DNA and phosphate ions with the $\mathrm{La}^{3+}$-morin complex would release it from the minor groove of DNA. The released $\mathrm{La}^{3+}$-morin complex, relative to its bound form, had a lower fluorescence yield. Thus, the quenching of fluorescence was observed. On the other hand, morin and its complex with $\mathrm{La}^{3+}$ had a similar fluorescence yield. Therefore, the addition of phosphate to the $\mathrm{La}^{3+}$-morin system should not cause any meaningful fluorescence quenching effect. A similar quenching effect, but to a lesser extent, was observed when a high concentration of $\mathrm{NaCl}$ instead of phosphate was used (Fig. 6). A high $\mathrm{Na}^{+}$concentration could

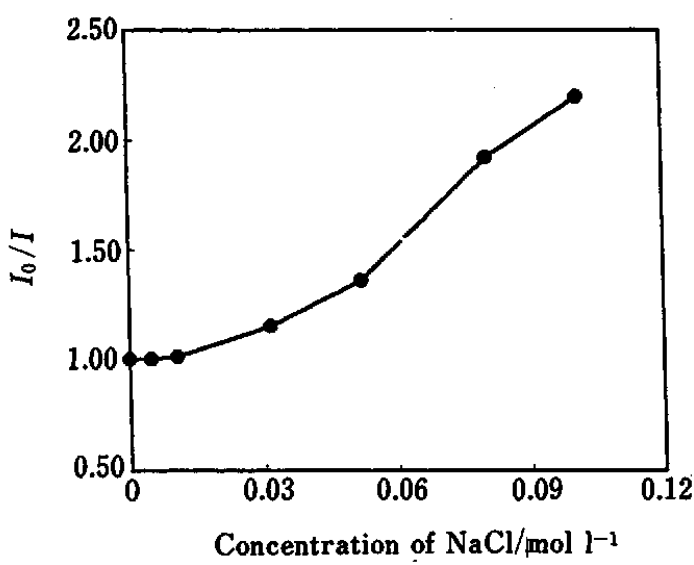

Fig. 6 The quenching effect of different concentrations of $\mathrm{NaCl}$ on the fluorescence of $1.0 \times 10^{-5} \mathrm{~mol} / 1 \mathrm{La}^{3+}+1.0 \times 10^{-5}$ $\mathrm{mol} / 1 \mathrm{morin}+4.0 \mu \mathrm{g} / \mathrm{ml}$ DNA at $\mathrm{pH} 5.5$.

neutralize the negative charges on the DNA backbone and, therefore, decrease the interaction between the DNA and the $\mathrm{La}^{3+}$-morin complex. The estimated Stern-Volmer quenching constant was $15.2 \mathrm{M}^{-1}$. These results indicated that the electrostatic interaction played an important role in groove binding of the $\mathrm{La}^{3+}$-morin complex to DNA. This was in agreement with a previous report ${ }^{9}$ that groove binding is mainly controlled by the electrostatic interaction. The binding of the DNA phosphate group to $\mathrm{La}^{3+}$-morin provides a morin complex with a relatively hydrophobic environment against nonradiactive deactivation, which seems to be responsible to the increase in the fluorescence intensity.

Influence of $\mathrm{pH}$ on the fluorescence of $\mathrm{DNA}-\mathrm{La}^{3+}$-morin complex

Due to the electrostatic properties of the interaction between morin and $\mathrm{La}^{3+}$ as well as that between the $\mathrm{La}^{3+}$ morin complex and DNA, the $\mathrm{pH}$ of the solution was expected to have a great influence on these interactions and fluorescence intensities. This was studied at $\mathrm{pH} 3$ 8; the results are shown in Fig. 7. It could be seen that the maximum fluorescence enhancement was observed only in the $\mathrm{pH}$ range of 4.5-6.5. This range roughly corresponded to the $\mathrm{p} K_{\mathrm{a}}$ values of $\mathrm{C}_{5}-\mathrm{OH}\left(\mathrm{p} K_{\mathrm{a}}=4.8\right)$ and $\mathrm{C}_{7}-\mathrm{OH}\left(\mathrm{p} K_{\mathrm{a}}=7\right)^{12}$ on ring $\mathrm{A}$ of morin. In this $\mathrm{pH}$ range, $\mathrm{C}_{3}-\mathrm{OH}$, which has a $\mathrm{p} K_{\mathrm{a}}$ value of 1 , is deprotonated. This suggested that deprotonation at both $\mathrm{C}_{5}-\mathrm{OH}$ and $\mathrm{C}_{3}-\mathrm{OH}$ provides morin with the $\mathrm{La}^{3+}$ binding affinity under our present experimental conditons, which forms the basis for the further binding of the $\mathrm{La}^{3+}$-morin complex to minor groove of the DNA. When $\mathrm{pH}$ was increased to above 7.0, ionization of $\mathrm{C}_{7}-\mathrm{OH}$ takes place, that makes morin molecule to take another negative charge that can not be involved in metal complex formation. Therefore, this was not in favor of an interaction between the $\mathrm{La}^{3+}$-morin complex and negatively charged DNA. A further increase in $\mathrm{pH}$ would cause the ionization of the hydroxyl group on ring 


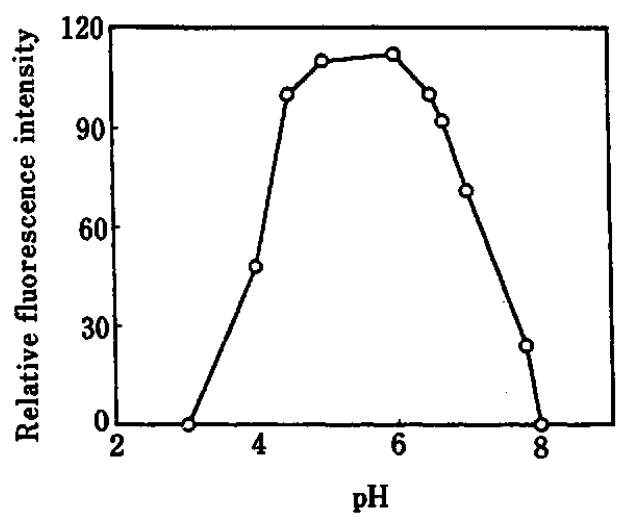

Fig. 7 Effect of $\mathrm{pH}$ on fluorescence intensity of $1.0 \times 10^{-5}$ $\mathrm{mol} / 1 \mathrm{La}^{3+}+1.0 \times 10^{-5} \mathrm{~mol} / 1 \mathrm{morin}+4.0 \mu \mathrm{g} / \mathrm{ml} \mathrm{DNA}$. The backgrounds from the samples without DNA were subtracted.

$\mathrm{C}$ and hydrolysis of $\mathrm{La}^{3+}$. Hence, no fluorescence enhancement was observed. On the other hand, too low of a $\mathrm{pH}$ would prevent $\mathrm{C}_{5}-\mathrm{OH}$ from ionization, and would cause DNA denaturation. Under this situation, the formation of both binary and ternary complexes were inhibited and no fluorescence enhancement was found.

\section{Analytical application}

The use of the $\mathrm{La}^{3+}$-morin complex as a fluorescent probe for a quantitative determination of DNA was investigated. According to the above mentioned study, a pH 5.5 buffer solution was used to obtain a high fluorescence enhancement.

Optimization of $\mathrm{La}^{3+}$ and morin concentration. The concentrations of $\mathrm{La}^{3+}$ and morin are optimized. The results were shown in Fig. 8. It can be seen that under the experimental conditions, the optimal concentrations for both $\mathrm{La}^{3+}$ and morin were $5.0 \times 10^{-6} \mathrm{~mol} / \mathrm{l}$. In a subsequent study, $1.0 \times 10^{-5} \mathrm{~mol} / 1 \mathrm{La}^{3+}$ and morin were used. Figure 8 also shows that the binding ratio of morin and $\mathrm{La}^{3+}$ was $1: 1$.

The influence of buffer concentration. Under the above mentioned optimized conditions, the influence of the buffer concentration was also studied. The results showed that the fluorescence enhancement decreased when either a too low or too high concentration of acetate buffer solution was used. A concentration of $0.02 \mathrm{~mol} /$ l gave the optimal result.

Comparison among lanthanide ions. Due to the similarity of lanthanide ions, ions other than $\mathrm{La}^{3+}$ were studied. The results showed that only $\mathrm{La}^{3+}, \mathrm{Lu}^{3+}, \mathrm{Y}^{3+}$ and $\mathrm{Gd}^{3+}$ showed a fluorescence enhancement of morin. Other $\mathrm{Ln}^{3+}$ are all paramagnetic and their complex did not show the $\mathrm{L} \rightarrow \mathrm{L}^{*}$ type luminescence. Although $\mathrm{Gd}^{3+}$ is also paramagnetic, the half-filled $4 \mathrm{f}$ electrons are stable, and show a weak interaction with the $\pi$ orbital of the ligand, and $\mathbf{L} \rightarrow \mathrm{L}^{*}$ luminescence was not completely destroyed. Therefore, a relatively weak $\mathrm{L} \rightarrow \mathrm{L}^{*}$ type luminescence was also observed. The fluorescence

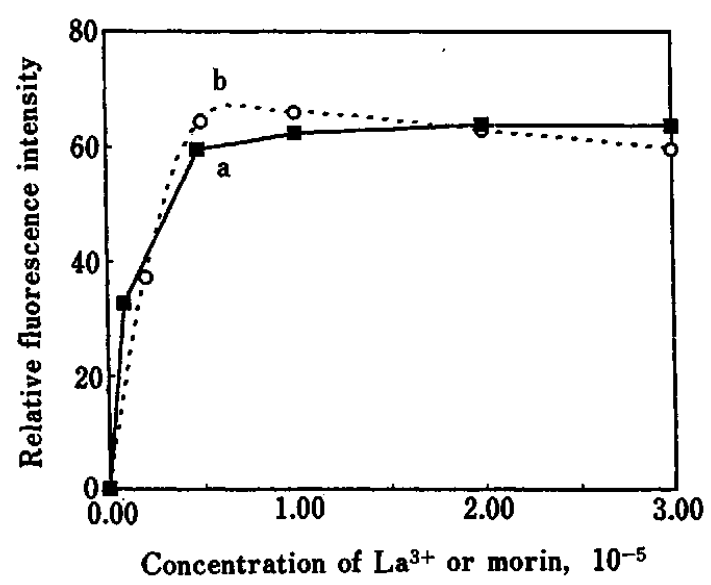

Fig. 8 Effect of the $\mathrm{La}^{3+}$ concentration on the fluorescence intensity of $1.0 \times 10^{-5} \mathrm{~mol} / 1 \mathrm{morin}+4.0 \mu \mathrm{g} / \mathrm{ml} \mathrm{DNA} \mathrm{(a)} \mathrm{and}$ the effect of the morin concentration on the fluorescence of $1.0 \times 10^{-5} \mathrm{~mol} / 1 \mathrm{La}^{3+}+4.0 \mu \mathrm{g} / \mathrm{ml}$ DNA (b) at $\mathrm{pH} 5.5$.

enhancement effect of DNA follows the order $\mathrm{Lu}^{3+}>$ $\mathrm{Y}^{3+}>\mathrm{La}^{3+}$. This order follows the decreasing ion radii or increasing binding abilities of these ions. Although DNA showed a stronger enhancement effect to the morin complexes of $\mathrm{Y}^{3+}$ and $\mathrm{Lu}^{3+}$, compared with that of $\mathrm{La}^{3+}$, the former two fluorescence systems were not stable and not suitable for analytical purposes. Thus, $\mathrm{La}^{3+}$-morin was selected for the DNA determination. The fluorescence from the $\mathrm{La}^{3+}$-morin system was very stable for at least half an hour.

Determination of natural DNA in synthetic samples.

Under the conditions established above, CT DNA was determined. The linear range for CT DNA is 0.04-10 $\mu \mathrm{g} / \mathrm{ml}$ and the correlation coefficient constant was 0.9975 . The lowest detection limit based on a signal/ noise of 2 was estimated to be $20 \mathrm{ng} / \mathrm{ml}$. The relative standard deviation for 7 measurements of $0.5 \mu \mathrm{g} / \mathrm{ml}$ DNA was $3.4 \%$. The sensitivity of this method is slightly lower than that based on ethidium bromide (EB), a commonly used fluorescence dye for DNA analysis, which has a detection limit of $10 \mathrm{ng} / \mathrm{ml} ;{ }^{13}$ however, EB is a strong carcinogenic reagent, and it binds well to both DNA and RNA, showing little selectivity to DNA.

The interference from protein (BSA) was studied by evaluating its influence on the determination of $4 \mu \mathrm{g} / \mathrm{ml}$ DNA. The results showed that $4 \mu \mathrm{g} / \mathrm{ml}$ of protein did not show any interference on the DNA determination, but that a 1.5-times excess of protein showed a serious quenching effect on the fluorescence.

Since natural DNA showed a much greater enhancement effect than did RNA, it may be possible to determine the concentration of DNA in the presence of RNA. The recoveries of $4.0 \mu \mathrm{g} / \mathrm{ml}$ DNA from different concentrations of RNA are summarized in Table 1. It can be seen that RNA lower than $1 \mu \mathrm{g} / \mathrm{ml}$ did not interfere with the DNA determination in this particular situation. 
Table 1 Determination of CT DNA in synthetic samples containing different amounts of RNA (the expected CT DNA concentration was $4.00 \mu \mathrm{g} / \mathrm{ml}$ for each sample)

\begin{tabular}{ccc}
\hline $\begin{array}{c}\text { RNA added } \\
\mu \mathrm{g} \mathrm{ml}^{-1}\end{array}$ & $\begin{array}{c}\text { CTDNA } \\
\text { recovery, \% }\end{array}$ & $\begin{array}{c}\text { Relative standard } \\
\text { deviation, } \%(n=6)\end{array}$ \\
\hline 0.5 & 101 & 2.0 \\
1.0 & 100 & 2.5 \\
2.0 & 114 & 1.8 \\
3.0 & 121 & 3.0 \\
4.0 & 130 & 2.9 \\
5.0 & 140 & 2.3 \\
\hline
\end{tabular}

In conclusion, the fluorogenic interaction between the $\mathrm{La}^{3+}$-morin complex and DNA was studied using various physiochemical methods. The results suggest a groovebinding mechanism. The $\mathrm{La}^{3+}$-morin complex electrostastically interacts with the phosphate groups of DNA, through which morin was brought near to the hydrophobic minor groove of DNA where further weak interactions, such as van der Waals and hydrogen bonding possibly contributed to the fluorescence enhancement. The specificity and sensitivity of $\mathrm{La}^{3+}$ morin made this complex a useful fluorescence probe for quantitative determination of natural DNA without any serious interference from either RNA or protein under the described experimental conditions.
This work was supported by National Natural Science Foundation of China.

\section{References}

1. G. M. Blackburn and M. J. Gait, "Nucleic Acids in Chemistry and Biology", pp. 297-326, IRL Press, Oxford, 1991.

2. F. S. Richardson, Chem. Rev., 82, 541 (1982).

3. M. Elbanowsiki, J. Photochem. Photobiol. A: Chem., 99, 85 (1996).

4. Y.X. Ci, Y. Z. Li and W. B. Chang, Anal. Chim. Acta, 248, 589 (1991).

5. Y. X. Ci, Y. Z. Li and X. J. Liu, Anal. Chem., 67, 1785 (1995).

6. S. T. Mullins, P. G. Sammes, R. W. West and G. Yahioglu, J. Chem. Soc. Perkin Trans 1, 1996, 75.

7. K. H. Ibsen and M. R. Urist, Proc. Soc. Exp. Bio. Med., 109, 797 (1962).

8. A. Cammarata and S. J. Yau, J. Med. Chem., 13, 93 (1970).

9. M. D. Luque de Castro, Talanta, 27, 645 (1980).

10. C. V. Kumar, R. S. Turner and E. H. Asuncion, $J$. Photochem. Photobiol. A: Chem., 74, 231 (1993).

11. M. Chien, A. P. Grollman and S. B. Horwitz, Biochemistry, 16, 3641 (1977).

12. M. H. Fletcher, Anal. Chem., 37, 550 (1965).

13. G. Y. Zhu, J. H. Yang and Z. K. Si, J. Chin. Rare Earth Soc., 2, 73 (1989).

(Received June 13,1997)

(Accepted October 3,1997) 